\title{
Augmented Reality and Virtual Reality in Physical and Online Retailing: A Review, Synthesis and Research Agenda
}

\author{
Francesca Bonetti ${ }^{\mathrm{a}}$, \\ Gary Warnaby ${ }^{\mathrm{b}}$, and \\ Lee Quinn ${ }^{\mathrm{a}}$ \\ ${ }^{\text {a }}$ School of Materials \\ The University of Manchester, United Kingdom \\ francesca.bonetti@postgrad.manchester.ac.uk \\ ${ }^{\mathrm{b}}$ Faculty of Business and Law \\ Manchester Metropolitan University, United Kingdom \\ g.warnaby@mmu.ac.uk
}

\begin{abstract}
Augmented reality (AR) and virtual reality (VR) have emerged as rapidly developing technologies used in both physical and online retailing to enhance the selling environment and shopping experience. However, academic research on, and practical applications of, AR and VR in retail are still fragmented, and this state of affairs is arguably attributable to the interdisciplinary origins of the topic. Undertaking a comparative chronological analysis of AR and VR research and applications in a retail context, this paper synthesises current debates to provide an up-to-date perspective - incorporating issues relating to motives, applications and implementation of AR and VR by retailers, as well as consumer acceptance - and to frame the basis for a future research agenda.
\end{abstract}

Keywords: augmented reality; virtual reality; retail; literature review; future research.

\section{Introduction}

The early 2000s saw the increasing adoption of advanced technologies by retailers in both their physical and online stores, to enhance both the store environment (i.e. the place where the product is bought or consumed), and the shopping experience (Pantano, 2015). This is especially true for what can be termed 'consumer-facing' technology; namely technologies and devices that the consumer experiences directly whilst in the physical or online store, such as interactive screens, online product visualisation and customisation, digital signage, etc. Amongst these technologies, augmented reality (AR) and virtual reality (VR) applications are rapidly evolving and increasingly used in retail environments (Javornik, 2016; McCormick et al, 2014).

Olsson et al (2013, p.288) define AR as a technique 'to combine real and computergenerated digital information into the user's view of the physical world in such a way they appear as one environment'. AR blends the virtual and real worlds (Huang and Liao, 2015), through a virtual layer that can add images, textual information, videos or other virtual elements to the user's viewing of physical environment in real time (Carmigniani et al, 2011). AR typically captures real-world data, usually with a digital camera in a webcam or mobile phone. Using devices such as smartphones or 
tablets, wearables (headsets), projectors or fixed interactive screens, AR can provide a creative and innovative way to capture consumers' attention by enabling them to interact with virtual products (McCormick et al, 2014; Reitmayr and Drummond, 2006). Experiential value is created through product simulation, media richness, sound, GPS data and videos (McCormick et al, 2014). The AR shopping experience enables consumers to interact smoothly with virtual items, thereby improving their visualisation of products and hopefully their subsequent image of the brand, which in turn, enhances buying intentions of consumers (Jiyeon and Forsythe, 2008).

In contrast, VR utilises a wearable device (typically a headset), which blocks out 'real world' sensory experiences to provide an arguably more engaging and innovative shopping environment by immersing users in virtual, entertaining 3-D worlds. Here, they can interact in real time and move physically within the virtual world, typically through movements of the head, but possibly also through motion tracking of limbs (Pantano, 2015; Dad et al, 2016; Sherman and Craig, 2002; Fuchs et al, 2011; Whyte, 2002). For VR to succeed, the headwear needs to be comfortable and confer credible immersive virtual effects. VR can therefore be defined in terms of a medium composed of interactive computer simulations that replace or augment the feedback to the user's actions through one or more senses, conferring the feeling of being psychologically immersed in the simulation - in other words, a virtual world (Sherman and Craig, 2002; Fuchs et al, 2011).

AR and VR's rapid development has attracted growing academic research interest, as well as further developments and applications. Originating as a research topic with some early exploratory work (Brody and Gottsman, 1999; Gold, 1993), only more recently has there been a more substantial consideration of these technologies in both the academic literature and in practice (Poushneh and Vasquez-Parraga, 2017; Javornik, 2016; Mann et al, 2015). However, a fragmented body of existing academic research and limited evidence of practical uses of AR and VR in a retailing context means that a coherent basis for further research is lacking. While this is arguably attributable to the interdisciplinary nature of the subject, there remains a pressing need for a critical examination and synthesis of the chronological developments and key current debates in AR and VR research and applications in retail, in order to locate future directions for a research agenda. Consequently, this review provides a twofold contribution: (1) it critically synthesises and examines current debates on AR and VR from different fields, and (2) it draws upon this synthesis to outline a future research agenda.

\section{Literature Review}

\subsection{Developments of research and applications of AR and VR in retail}

From its origins in cinematography in the 1950s, AR has evolved enormously. Since the 1990s, mobile AR and wearable computers started to be developed and put to use, gaining increasing attention in computer science fields, together with the areas of VR, 3-D technology and mobile technology (Javornik, 2016). Since then, the technology has also been applied in retail, gaming, medicine, navigation and education contexts. In the case of VR, early examples of the use of this medium date back to the 1970s in 
the aviation industry. Only recently has the use of VR been more widely extended with the development of virtual technologies (Sherman and Craig, 2002). Another influencing factor has been a significant increase in the intrinsic power of computers and especially the possibility of creating computer-generated images and enabling real-time interaction between the user and the real world through VR systems (Fuchs et al, 2011; Craig et al, 2009). Consequently, both these technologies have generated much interest, arising from their potential impact as disruptive technologies in various contexts. Fig. 1 provides a comparative timeline of developments in AR and VR research in a specific retail context, indicating the disciplinary origins of the research.

AR research

$1990 \mathrm{~s}$

Exploration of uses in augmented commerce (Brody and Gottsman, 1999)

2000 s

retail environment (Sukaviriya et al,
Form of experiential marketing:
long-term benefits: increase
customer loyalty (Bulearca and
Tamarian, 2010)

$$
\begin{aligned}
& \text { Contribution to shopping } \\
& \text { experience; wide adoption in retail } \\
& \text { (Tabusca, 2014) } \\
& \text { Consumer engagement - immersive } \\
& \text { AR (Scholz and Smith, 2016) }
\end{aligned}
$$

Fun factor in virtual fitting rooms

(Pachoulakis and Kapetanakis,

2012)

Key: Management iournals: Technology journals; Marketing journals

Fig. 1. Comparative timeline of AR and VR research

Use of AR technology in retailing occurs at various touchpoints of the consumer journey - physical, mobile and online (Javornik, 2016; Carmigniani et al, 2011). Research and applications of AR in retail indicate that it has been regarded as facilitating experiential marketing (Bulearca and Tamarjan, 2010). Indeed, early studies on AR explored its uses in augmented commerce through shopping agents, to bridge the gap between electronic and traditional commerce (Brody and Gottsman, 1999). In the case of VR, early research considered a visual simulation system called Visionary Shopper, which provided a shopping environment and experience as close

Simulation of shopping environment Gold, 1993)

Immersive aspect of virtual and interactivity (Leinfuss, 1996)

Virtual store interfaces affecting online consumer behaviour differently from 2004) through VR technology (Ballantine, 2005; Kim and Forsythe, 2008; Vrechopoulos et al, 2009) al, 2013)

Continuous developments to improve

Consumers' positive response in physical retail; enhancing shopping experience (Mann et al, 2015)

\section{online shoppers' \\ enjoyment and engagement}

(Papagiannidis et al, 2013; Gadalla et )

Online shopping environment 8; 
as possible to reality, where users could interact with products. This system was tested on shoppers and was regarded as being an enjoyable and fun experience, thereby promising more interactive technologies in the future (Gold, 1993). The importance of interactivity in VR using web capability to simulate reality also emerged in the 1990s (Leinfuss, 1996), emphasizing the importance of familiarisation with VR technologies and concepts. These early studies on virtual environments assessed the degree of immersion of the technology, including the inclusiveness of displays used, surroundings, etc. arguing that human beings were becoming 'more and more intertwined with computers' (Slater and Wilbur, 1997, p.614). Applications of VR devices for real-world modification began with Electrolux announcing the opening of VR showrooms allowing consumers to build virtual kitchens using instore computers (Williamson, 1996) and Sainsbury's pioneering use of VR technology to decrease development costs and improve the results of supermarket redesigns through an interactive VR headset (Sainsbury's, 1995). Entertainment giant Blockbuster was an early adopter of VR to create a virtual warehouse through simulation (Batiz, 2001), and in 1999 Burger King used 3-D technology to simulate a new retail store concept and fully understand the design, thus enabling interaction (Summerour, 2001).

Research during the 2000 s on AR used in a physical retail environment (through interactive displays, which predicted users interacting with steerable technology and triggering information on the product, promotions and locations - see Sukaviriya et al, 2003), highlighted both its functional and hedonic aspects. Early applications of $\mathrm{AR}$ in retailing include virtual try-on using personalised or non-personalised virtual models to simulate the appearance of apparel product combinations on a body form, rotating the model through front and back views that can be enlarged (Lee et al, 2006). There were also contrasting views on the long-term benefits of AR, ranging from it being perceived as being exclusively a promotional tool (Woods, 2009), to fostering positive consumer-brand relationships (Owyang, 2010) and consumer satisfaction by generating an experiential value effect (Chou, 2009). Bulearca and Tamarjan's (2010) study also indicated that use of AR was beneficial for companies and brands in that it could lead to increased customer loyalty, with research on instore and online adoption of AR evidencing consumers' positive responses to the technology, making them engage with retailers and more willing to go shop at stores offering this technology (Pantano, 2015; McCormick et al, 2014).

In the case of VR, and in particular virtual store layout, while some state that it has a critical influence on traffic and sales (Lohse and Spiller, 1998), others claim that the characteristics of the virtual layout determine shoppers' willingness to buy online (Burke, 2002). Vrechopoulos et al (2004) suggest that a virtual grocery store layout significantly affects online consumer behaviour. However, predictions generated from conventional retail store layout theory do not generally correspond in a virtual setting, due to consumers' ability to reach any place in the virtual store directly. Thus, more consumer-friendly virtual shopping interfaces would further influence consumers' buying behaviour online. This is consistent with Ballantine's (2005) findings indicating that the level of interactivity and amount of information provided by the online shopping environment through the virtual interface strongly influences consumer satisfaction, thus impacting on consumer behaviour online. Subsequent 
studies on consumer behaviour in VR retailing in an online context showed that VR's applications enabling shoppers to interact with the product (e.g. apparel) enhance the hedonic value of the shopping experience (Kim and Forsythe, 2008), and information agents (e.g. avatars) have a positive effect on consumer behaviour when static information on the website is limited (Sivaramakrishnan et al, 2007). Vrechopoulos et al (2009) indicate that VR layout does not influence behaviour, and that consumers visit virtual worlds mainly for entertainment and socialising reasons.

More recently, whilst Kang's (2013) study on AR use for apparel e-shopping identified that consumers' utilitarian performance expectancy (e.g. convenience, emotional, monetary and social values) is positively related to usage intentions and hedonic performance, expectancy was not. Other studies show the impact of AR on users' experience, satisfaction, enhancement of the perception of reality and overall a fun, pleasant and personalised experience to be relevant for users (Poushneh and Vasquez-Parraga, 2017). This was further supported by Pachoulakis and Kapetanakis' (2012) findings, where it emerged that AR used for virtual fitting rooms, through the user's computer or phone camera (allowing users to virtually see how a dress would fit on them through a virtual changing room from their homes - see Kumari and Bakan, 2015; Kang, 2013), was regarded as contributing to the 'fun factor' of shopping (Pachoulakis and Kapetanakis, 2012).

An explosive growth of mobile AR subsequently occurred, taking advantage of widely distributed personal mobile technology such as smartphones and tablets (Craig, 2013; Javornik, 2016). This consists of a form of consumer-led interactions, personalisation, customisation and AR (Magrath and McCormick, 2013), such as IKEA's AR app 'being able to measure the width and height of the real-life room seen through the camera's objective and then render a very accurate piece of furniture, in relation to the rest of the actual surrounding environment' (Tăbușcă, 2014, p.5). Studies of mobile apps for shopping using AR indicate that take-up is set to go mainstream due to relatively high user satisfaction linked to experiential benefits along with advantages to retailers (Dacko, 2016). Moreover, in-store large AR mirrors also constitute a form of AR application (Craig, 2013). For example, US virtual technology company ModiFace has created an augmented reality mirror simulating the effects of makeup, skincare and teeth whitening products to offer consumer a more realistic try-before-you-buy shopping experience (Podeszwa and Baron, 2016). Similarly, fashion retailer Rebecca Minkoff's AR mirrors fit garments to the consumer's body shape by holding them up against the individual's body (McCormick et al, 2014).

Overall, Scholz and Smith (2016) stress the importance for retailers of adopting immersive AR, crafting experiences that generate value for consumers, and thus the importance of focusing on consumer engagement. Regarding VR, more recent research states that VR systems are failing to keep up with users' high standards and expectations in terms of user experience and usability (Alshaal et al, 2016). However, Papagiannidis et al's (2013) findings show that the use of VR transcends environmental boundaries, where enjoyment and engagement positively influence user satisfaction when choosing apparel products in a virtual store, thus influencing purchase intention. In particular, features of VR technologies help enhance the social 
experience, virtual trial of products and co-production opportunities (Gadalla et al, 2013). Amongst the latest applications, Tommy Hilfiger offers shoppers in their main flagship stores a 3-D virtual trip with a front-row view of the brand's fashion show to entertain and inspire consumers, highlighting items of the collection that they would see in the video of the runaway show (Tabuchi, 2015). Users virtually sit not far from models, and the headset reacts to their movements: they can look in all directions; by turning around, they can see rows of guests almost touchable and moreover they can virtually go to the backstage area of the show (Howland, 2016). Beauty retailer Sephora created a virtual try-on feature app in selected stores which can simulate cosmetics on a person's face in real-time and 3D (Nesbit, 2014). Results from Mann et al (2015) showed that consumers respond to the use of VR technology in physical stores positively, in which VR delivers more appealing shopping experiences than traditional store environments.

\subsection{The interdisciplinary nature of $A R$ and $V R$ research}

Drawing on the comparative timelines of AR and VR research in Fig. 1, it is important to analyse its various disciplinary origins. The interdisciplinary nature of the subject and different academic areas of research - ranging from technology to management and marketing - are evident. The fragmented nature of research into AR and VR arguably emanates as a consequence of these different perspectives. Further exploration of this fragmented research context is needed to develop a future research agenda.

\section{Current debates in AR and VR research and applications}

The above review of the chronological development of AR and VR research and applications in retail has served as a basis for synthesising and framing some key current debates in the field. These are structured in terms of Adoption, Applications and Acceptance. These areas are now examined in more detail to help shed light on the fragmented research to date, and hopefully assist managers in making informed decisions when designing their retailing and marketing strategies.

\subsection{Retailers' adoption of AR and VR}

From this overview of the literature on AR and VR, contrasting perspectives emerged from retailers' adoption of these technologies. In some cases, challenges related to taking the risk and investing in these new forms of technology, without knowing exactly the expected generated profits, and against only the promise of implementation within the shopping experience, prevent several retailers from adopting them (Piotrowicz and Cuthbertson, 2014). This is the case for VR, where some critics claimed that, although this technology helps enhance the in-store experience, it is more a tool to gain consumers' attention than a viable in-store solution. This is because it is costly and time-consuming (it takes a lot of floor space and resources and is only used by few shoppers a day), and most of the time helps only build the brand whilst generating minimal return on investment (Milnes, 2016). Moreover, when a new technology is adopted and implemented by retailers, they should promote the new tool to make potential users aware of it and provide all necessary relevant information (Zagel, 2016). Low level of technology expertise and 
commitment of employees and sales associates can also represent a challenge for retailers, especially where training is necessary to make sales associates comfortable with the new tools in order to communicate and promote them properly to potential users (Piotrowicz and Cuthbertson, 2014).

Benefits also emerged from retailers' adoption of AR and VR, including overcoming operational barriers, saving time and cutting costs; for example, Sainsbury's use of VR technology to decrease development costs and improve the results of supermarket redesigns through an interactive VR headset (Sainsbury, 1995). In other instances, the use of these advanced technologies by retailers helped enhance the shopping experience, across all retail channels. Indeed, Pantano (2015) suggests these technologies could contribute to creating new marketing experiences. This is particularly the case with product categories such as apparel. Here in particular, pureplay online retailers may have to compensate for some of the perceived disadvantages of selling online; thus not having a physical store consisting of design and tactile factors, such as merchandise that consumers can touch and try on to make comparisons of product quality, size and style. Finally, early adopters of new emerging AR and VR technologies benefit from being perceived as highly innovative and market leaders regarding the use of technologies by consumers and competitors, (as in the case of both Burberry's and Rebecca Minkoff's use of AR mirrors), as opposed to merely keeping up with competition (Teo and Pian, 2003; Pantano, 2014).

\subsection{AR and VR applications in retail}

Current applications and implementation of AR include online use of personalised or non-personalised virtual models to virtually try on clothes and simulate product combinations (Lee et al, 2006). Virtual fitting rooms allow individuals to use their camera to virtually see how a dress would fit on them (Kumari and Bakan, 2015; Kang, 2013). Such functionality is offered by Zugara through the e-commerce solution 'Webcam Social Shopper', providing the ability to let consumers 'hold' different items of clothing up against themselves and see how they would look (Zugara, 2015). Mobile apps constitute a form of consumer-led interactions and AR (Magrath and McCormick, 2013). In-store use of AR is possible through digitallyenhanced mirrors, used for fitting purposes and to offer recommendations, personalised offers and product location in the store (Zagel, 2016). UK fashion retailer Topshop, for instance, launched AR fitting rooms in selected stores for consumers' virtual trial of products; Bloomingdale's allows shoppers walking past its store to virtually try on glasses from the street by aligning glasses on the user's nose (Grinspan, 2012). Amongst other VR devices currently being used by retailers, Sephora offers in-store virtual try on of cosmetics to enhance the shopping experience; VR headsets have been adopted by some fashion retailers including Tommy Hilfiger and Dior (Howland, 2016) - the latter has installed Dior Eyes in selected stores to transport shoppers to 3D catwalk shows and virtually highlight the craftsmanship behind the creation of the products. VR creates experiences also in a home context, allowing consumers to shop from home by seeing the item and interacting with it. VR in online retailing is increasingly developing to substitute input devices (e.g. mouse, keyboard) with more natural user interactions (e.g. gestures such as tapping and swiping) to improve the user experience (Alshaal et al, 2016). 


\subsection{Consumers' acceptance of AR and VR}

Important reactions of consumers driving the acceptance and use of AR and VR systems emerged from this review. Consequently, relevant managerial implications can be derived, especially as technological progress and retailers' adoption of innovative technologies do not necessarily and always correspond to consumers' acceptance and usage of new forms of technology. Davis' (1989) technology acceptance model (TAM), and its more recent extensions, has traditionally been considered a key tool to measure the discrepancy between the technological innovations which both consumers and organisations are expected to use, and those that they will accept and use. Amongst the key factors are the perceived usefulness of technology (PU) in enhancing the user's activity, and the perceived ease-of-use (PEOU) of using a particular system. Moreover, user's individual differences and characteristics and attitudes about the technology also act as external variables influencing a user's PU and PEOU (Gelbrich and Sattler, 2014).

Consumers react positively to AR's entertaining and experiential value, interactivity, PU and contribution to speeding-up the processes of purchase decision-making, incorporating both its functional and hedonic roles (Huang and Liao, 2015). In particular, consumers' levels of cognitive innovativeness play an important role in influencing their behaviours towards accepting and using AR. Here, consumers with high cognitive innovativeness put more emphasis on usefulness, aesthetics and service excellence presented by AR. Positive reactions emerged from the use of AR by online shoppers. AR helps decrease the perceived cognitive risk arising from the uncertainty of not seeing products, and their combinations. Moreover virtual interaction before buying online can deliver product information that closely resembles the information acquired from examining the product directly, thus stimulating mental imagery (Poncin and Mimoun, 2014). Considering VR, results from Mann et al (2015) highlight consumers' positive reaction towards VR technology in physical stores, enhancing the shopping experience, and thus making it more appealing than with traditional merchandising techniques. However, economic and social factors may inhibit consumers' acceptance, for instance relating to high costs and social acceptability associated with VR headsets. Overall, consumers' understanding of how to use new technology (and its working properly) is fundamental to obtain users' positive reactions that lead to the acceptance of technologies, as the opposite can reduce PU, PEOU, intuitiveness and lead to frustration and dissatisfaction (Lee et al, 2012).

\section{Conclusion}

The fragmented nature of academic and applied research on AR and VR has arisen as a consequence of the interdisciplinary nature of the subject and the different academic domains of research, ranging from technology, to marketing and management contexts. Based on a critical review and synthesis of the chronological development of key debates on AR and VR research and retail applications, it becomes possible to frame a future research agenda. Possible directions to better realise the potential of $\mathrm{AR}$ and VR in the retail context are outlined below. 
Research indicates a need to develop more efficient and enhanced consumer-friendly shopping interfaces for the successful adoption and implementation of AR and VR in online retailing. Here, a shared understanding, and cooperation, between different disciplines (including Marketing, Retailing, Human-Computer Interaction, etc.) is key to designing effective virtual shopping environments (Vrechopoulos et al, 2004; Ballantine, 2005). Collaboration between AR and VR technology providers and retailers also emerges as an important factor. Joining forces and skills to develop marketing and retailing strategies that effectively enrich and enhance consumers' shopping experience by comparing views, sharing insights and knowledge of consumers' characteristics towards acceptance of technology, dealing with barriers and requirements for implementation, needed innovations, market trends, etc. will be important (Dacko, 2016; Poushneh and Vasquez-Parraga, 2017). Conversely, some critics have claimed that although VR is helping enhance the in-store experience, there is a risk that it becomes more a tool for gaining consumers' attention than a viable in-store solution. Thus, it will only be adopted by a limited number of retailers (Javornik, 2016), particularly as the technology is costly and time-consuming to implement while its return on investment may be minimal (Milnes, 2016). Consequently, this is more likely to be a special technology for a small number of experience-driven retailers. Further research on how these phenomena are evolving and including different disciplines is needed to gain a fuller understanding.

Regarding consumers' acceptance of these advanced technologies, in 2016 Facebook founder Mark Zuckerberg predicted that future VR headsets would look like a normal pair of glasses (Lopez, 2016). This could potentially increase uptake by a broader range of shoppers by making them more socially acceptable (e.g. discrete and subtle), useful, easy and natural to interact with, and even fashionably acceptable (Carmigniani et al, 2011; Poushneh and Vasquez-Parraga, 2017). As for the near future, mobile technology offers a strong potential to be an important driver for consumer adoption of VR. Although consumers may currently be reluctant to purchase a VR headset, having the facility to view VR experiences and interact with products through their mobile devices will lower the barriers to adoption because they are already familiar and comfortable with the technology involved (Howland, 2016). However, AR and VR advocates have acknowledged different challenges. From a security and privacy perspective, AR systems, although very advanced, at the same time do not protect the user's privacy, thus allowing others to access or see information (Carmigniani et al, 2011). This can be an advantage, as users do not need to wear or carry any extra viewing device, thus making the technology more acceptable; however, it represents a problem concerning privacy and security of information. AR and VR technologies are constantly evolving to enhance online retailing; however, further research is needed to assess consumers' evolving acceptance and usage of these technologies, examining whether perceived barriers concerning privacy, acceptability and price accessibility are likely to be overcome and the important managerial implications deriving from such insights.

Overall, this review offers a number of contributions. It provides a detailed and critical review and synthesis of the chronological developments in AR and VR research and their application in a retail context. It also synthesises and examines important and current debates on the subject across different domains. Consequently, 
it signposts a clearer framework for locating future research inquiry and it highlights a research agenda that could provide the catalyst for this process.

\section{References}

Alshaal, S. E., Michael, S. and Pamporis, A. (2016). Enhancing Virtual Reality Systems with Smart Wearable Devices, Mobile Data Management (MDM), 17th IEEE International Conference on. Vol. 1. IEEE.

Ballantine, P. W. (2005). Effects of interactivity and product information on consumer satisfaction in an online retail setting, International Journal of Retail \& Distribution Management, 33.6:461-471.

Batiz, G. (2001). Virual reality. Warehousing Management, 8(5):31-32.

Brody, A. B. \& Gottsman, E J. (1999). Pocket BargainFinder: a handheld device for augmented commerce, International Symposium on Handheld and Ubiquitous Computing. Springer Berlin Heidelberg.

Bulearca, M. \& Tamarjan, D. (2010). Augmented reality: A sustainable marketing tool, Global Business and Management Research: An International Journal. 2:237-252.

Burke, R. R. (2002). Technology and the customer interface: What consumers want in the physical and virtual store, Journal of the Academy of Marketing Science, 30(4): 411432.

Carmigniani, J., Furht,B., Anisetti,M., Ceravolo,P., Damiani,E. \& Ivkovic,M. (2011). Augmented reality technologies, systems and applications, Multimedia Tools and Applications. 51:341-377.

Chou, H. J. (2009). The effect of experiential and relationship marketing on customer value: A case study of international American casual dining chains in Taiwan, Social Behaviour and Personality, 37(7):993-100.

Craig, A. B. (2013). Understanding augmented reality: concepts and applications. Newnes.

Craig, A. B., Sherman, W. R. \& Will, J. D. (2009). Developing virtual reality applications: Foundations of effective design. Morgan Kaufmann.

Dacko, S. G. (2016). Enabling smart retail settings via mobile augmented reality shopping apps, Technological Forecasting and Social Change.

Dad, A. M., Barry, D. \& Rehman, A. A. (2016). 3D Servicescape Model: Atmospheric Qualities of Virtual Reality Retailing, International Journal of Advanced Computer Science and Applications. 7(2):25-38.

Davis, F.D. (1989). Perceived usefulness, perceived ease of use, and user acceptance of information technology, MIS Quarterly, 13(3):319-340.

Fuchs, P., Moreau, G. \& Guitton, P. (2011). Virtual reality: concepts and technologies. CRC Press.

Gadalla E., Keeling K. \& Abosag I. (2013). Metaverse-retail service quality: A future framework for retail service quality in the 3D internet, Journal Of Marketing Management, 29(13-14):1493-1517.

Gelbrich, K. \& Sattler, B. (2014). Anxiety, crowding, and time pressure in public self-service technology acceptance, Journal of Services Marketing, 28(1):82-94.

Gold, L. N. (1993). Virtual Reality Now a Research Reality, Marketing Research. 5(4):50-51.

Grinspan, I. (2012). Try On Sunglasses from the Street in Bloomingdale's New Display, http://ny.racked.com/2012/4/19/7728253/try-on-sunglasses-from-the-street-inbloomingdales-interactive-display \#4571298, accessed: 18.05.2015.

Howland, D. (2016). The new realities of VR and retail, http://www.retaildive.com/news/thenew-realities-of-vr-and-retail/414482/, accessed: 29.05.2016

Huang, T.-L. \& Liao, S. (2015). A model of acceptance of augmented-reality interactive technology: the moderating role of cognitive innovativeness, Electronic Commerce Research. 15(2):269-295. 
Javornik, A. (2016) .Augmented reality: Research agenda for studying the impact of its media characteristics on consumer behaviour, Journal of Retailing and Consumer Services. 30:252-261.

Jiyeon, K. \& Forsythe, S. (2008). Adoption of Virtual Try-on technology for online apparel shopping, Journal of Interactive Marketing, 22(2):45-59.

Kang, M. J.-Y. (2014). Augmented reality and motion capture apparel e-shopping values and usage intention, International Journal of Clothing Science and Technology, 26.6:486499.

Kim, J., \& Forsythe, S. (2008). Adoption of virtual try-on technology for online apparel shopping, Journal of Interactive Marketing, 22(2):45-59.

Kumari, N. \& Bankar, S. (2015). A Real Time Virtual Fitting Room Application, International Engineering Research Journal (IERJ), 1(4):122-125.

Lee, H.-H., Fiore, A. M. \& Kim, J. (2006). The role of the technology acceptance model in explaining effects of image interactivity technology on consumer responses', International Journal of Retail \& Distribution Management, 34(8):621-644.

Lee, L., Meyer, T. \& Smith, J. S. (2012). Reinventing the Customer Experience: Technology and the Service Marketing Mix, In Kandampully, J. (Ed.) Service Management: The New Paradigm in Retailing, Springer New York, pp. 143-160.

Leinfuss, E. (1996). Virtual worlds, real applications. InfoWorld, 18(48):57-59.

Lohse, L. G., \& Spiller, P. (1998). Electronic shopping: How do customer interfaces produce sales on the internet, Communications of the ACM, 41(7):81-87.

Lopez, N. (2016). Facebook says VR headsets will look like Ray-Bans in 10 years, http://thenextweb.com/facebook/2016/04/12/facebook-says-will-vr-headsets-sizenormal-glasses-next-10-years/\#gref, accessed: 30.05 .2015

Magrath, V. \& McCormick, H. (2013). Marketing design elements of mobile fashion retail apps, Journal of Fashion Marketing and Management: An International Journal, 17(1):115-134.

Mann, M.K., Liu-Thompkins, Y., Watson, G.S. \& Papelis, Y.E., (2015). A Multidisciplinary Examination of 3D Virtual Shopping Environments: Effects on Consumer Perceptual and Physiological Responses, In Ideas in Marketing: Finding the New and Polishing the Old. Springer International Publishing, pp. 752-755.

McCormick, H., Cartwright, J., Perry, P., Barnes, L., Lynch, S. \& Ball, G. (2014). Fashion retailing - past, present and future, Textile Progress, 46(3):227-321.

Milnes, H. (2016). VR isn't scalable': Bursting the in-store digital tech bubble, http://digiday.com/brands/retailtech2016-vr-isnt-scalable-bursting-the-in-store-digitaltech-bubble/, accessed: 30.05.2016.

Nesbit, T. (2014). Sephora's Augmented Reality Mirror Adds Virtual Makeup To Customers' Faces, http://www.psfk.com/2014/06/sephora-augmented-reality-mirror-try-onmakeup.html?utm, accessed: 26.05.2016.

Olsson, T., Lagerstam, E., Kärkkäinen, T. \& Väänänen, K. (2013). Expected user experience of mobile augmented reality services: a user study in the context of shopping centres, Personal and ubiquitous computing, 17(2):287-304.

Owyang, J. (2010). Disruptive Technology - The New Reality Will be Augmented, Customer Relationship Management Magazine, 32(2):32-33.

Pachoulakis, I. \& Kapetanakis, K. (2012). Augmented reality platforms for virtual fitting rooms, The International Journal of Multimedia \& Its Applications, 4.4:35.

Pantano, E. (2014). Innovation drivers in retail industry, International Journal of Information Management, 34(3):344-350.

Pantano, E. (2015). Successful Technological Integration for Competitive Advantage in Retail Settings. US, IGI Global.

Papagiannidis S, Pantano E, See-To E. \& Bourlakis M. (2013). Modelling the determinants of a simulated experience in a virtual retail store and users' product purchasing intentions, Journal Of Marketing Management, 29(13-14):1462-1492. 
Piotrowicz, W. \& Cuthbertson. R. (2014). Introduction to the special issue information technology in retail: toward omnichannel retailing, International Journal of Electronic Commerce, 18(4):pp.5-16.

Podeszwa, M. \& Baron, K. (2016). CES: ModiFace Updates AR Beauty Makeover Tool, http://blog.decodedfashion.com/stories/ces-modiface-updates-ar-beauty-makeover-tool, accessed: 15.01.2016.

Poncin, I. \& Mimoun, M. S. B. (2014). The impact of "e-atmospherics" on physical stores, Journal of Retailing and Consumer Services, 21(5):851-859.

Poushneh, A. \& Vasquez-Parraga, A. Z. (2017). Discernible impact of augmented reality on retail customer's experience, satisfaction and willingness to buy, Journal of Retailing and Consumer Services ,3:229-234.

Reitmayr, G. \& Drummond, T. (2006). Going out: robust model-based tracking for outdoor augmented reality, Proceedings of the 5th IEEE and ACM International Symposium on Mixed and Augmented Reality. IEEE Computer Society.

Sainsbury (1995). Sainsbury's wins race to develop world's first virtual reality supermarket, Assembly Automation, 15(4):5.

Scholz, J. \& Smith, A. N. (2016). Augmented reality: Designing immersive experiences that maximize consumer engagement, Business Horizons, 59.2:149-161.

Sherman, W. R. \& Craig, A. B. (2002). Understanding virtual reality: Interface, application, and design. Elsevier.

Sivaramakrishnan, S., Wan, F. \& Tang, Z. (2007). Giving an "e-human touch" to e-tailing: The moderating roles of static information quantity and consumption motive in the effectiveness of an anthropomorphic information agent, Journal of Interactive Marketing, 21(1):60-75.

Slater, M. and Wilbur, S. (1997). A framework for immersive virtual environments (FIVE): Speculations on the role of presence in virtual environments, Presence: Teleoperators and virtual environments, 6.(6):603-616.

Sukaviriya, N., Podlaseck, M., Kjeldsen, R., Levas, A., Pingali, G. \& Pinhanez, C. (2003). Augmenting a retail environment using steerable interactive displays, Extended Abstracts on Human Factors in Computing Systems, ACM, CHI'03: 978-979.

Summerour, J. (2001). Virtual reality. Progressive Grocer, 80(8):25-28.

Tabuchi, H. (2015). Tommy Hilfiger Introduces Virtual Reality Headsets for Shoppers, http://www.nytimes.com/2015/10/21/business/tommy-hilfiger-introduces-virtualreality-headsets-for-shoppers.html, accessed: 03.02.2015

Tăbușcă, A. (2014). Augmented reality-need, opportunity or fashion', Journal of Information Systems \& Operations Management, 8(2):5-10.

Teo, T. S. H. \& Pian, Y. (2003). A contingency perspective on Internet adoption and competitive advantage, European Journal of Information Systems, 12(2):78-92.

Vrechopoulos, A. P., Keefe, R. M. O., Doukidis, G. I. \& Siomkos, G. J. (2004). Virtual store layout: an experimental comparison in the context of grocery retail, Journal of Retailing, 80.1:13-22.

Vrechopoulos , A., Apostolou, K. \& Koutsiouris, V. (2009). Virtual reality retailing on the web: emerging consumer behavioural patterns, The International Review of Retail, Distribution and Consumer Research, 19(5):469-482

Whyte, J. (2002). Virtual reality and the built environment. Routledge.

Williamson, M. (1996). Virtual shopping takes stage at retail show. Computing Canada, 22, 20.

Woods, A. (2009). Augmented Reality: Reality Check, Revolution Magazine, April, 36-39.

Zagel, C. (2016). Service Fascination. Germany: Springer Fachmedien Wiesbaden.

Zugara (2015). The Webcam Social Shopper (WSS), http://zugara.com/virtual-dressing-roomtechnology/webcam-social-shopper\#prettyPhoto[]/3/, accessed: 05.04.2015. 